\title{
Resilient flood risk strategies: institutional preconditions for implementation
}

\author{
Berry Gersonius $^{1}$, Arwin van Buuren ${ }^{2}$, Marit Zethof $^{3}$ and Ellen Kelder ${ }^{4}$
}

\begin{abstract}
There is a growing recognition of resilience enhancement as an additional objective for adaptation. This will typically involve enhancing the preparedness and capacity to respond to the impacts of climate change. Within flood risk practice, resilient strategies focus on reducing impacts from flooding through better prevention and preparedness. Such strategies will not only reduce existing risk levels, but could also make the social-ecological system more robust for extreme flood events. This is because they seek to prevent those impacts on the system from which recovery is extremely difficult without outside help. Besides that, resilient strategies increase the prospect for the realization of cobenefits, particularly when measures are selected within the spatial domain. Implementing resilient strategies, however, faces many difficulties, particularly in countries like the Netherlands and Poland where prevalent governance arrangements are aimed to facilitate resistant strategies, focusing exclusively on flood protection. We analyzed these implementation difficulties for the Island of Dordrecht, which is a front-runner case of resilient flood risk governance in the Netherlands. A theoretical framework based on relevant issues regarding governance arrangements was used to reflect on the identified gaps and barriers. Although all issues played a role in the case study, there seem to be no generic institutional design parameters that have to be applied for implementing resilient strategies. Even in the current institutional regime, it is possible to find ways of implementing a resilient strategy. The more general institutional precondition has to do with the political willingness to allow for collaboration and experimentation and to enable a more flexible use of current principles and rules.
\end{abstract}

Key Words: adaptation; flood risk governance; institutional feasibility; resilience; system robustness

\section{INTRODUCTION}

Governments in Europe increasingly invest in adaptation to the impacts of climate change, such as more floods and droughts. The Netherlands, for example, has decided to invest approximately $€ 1$ billion per year in flood risk management and freshwater supply until the end of 2028 (Van Alphen 2015), and the European Union (EU) has earmarked $20 \%$ of its budget for climate-related investments (EC 2013a). This 20\%-threshold will be realized, among other outcomes, by mainstreaming adaptation into EU sectoral policies and funds for cohesion, energy, transport, and agriculture. With these levels of investment, it is essential to ensure the effectiveness and cost-efficiency of adaptation strategies. The former is usually framed in terms of reducing risk, e.g., flood or drought risk, to a legally required or societally acceptable level, while the latter is about reducing risk to an economically "optimum" level. In the recent past, resilience enhancement has emerged as an additional objective for adaptation. This is evident from, for example, the overall aim of the EU Adaptation Strategy, which is "to contribute to a more climate resilient Europe" (EC 2013b). According to the Adaptation Strategy, this means enhancing the preparedness and capacity to respond to the impacts of climate change, though a specific meaning of resilience has not been provided.

The use of resilience as a frame for viewing adaptation, and flood risk management in particular, is critically dependent on a wellspecified meaning of resilience (Brand and Jax 2007). In socialecological sciences, resilience is typically defined from a holistic systems perspective in which systems are connected to each other and influence each other. These systems are inherently dynamic. This necessitates that systems will continually change and adapt (Folke et al. 2010). In this sense, resilience has been defined as "the capacity of linked social-ecological systems to absorb recurrent disturbances such as hurricanes or floods so as to retain essential structures, processes, and feedbacks. Resilience reflects the degree to which a complex adaptive system is capable of selforganization (versus lack of organization or organization forced by external factors) and the degree to which the system can build capacity for learning and adaptation" (Adger et al. 2005:1036). For flood risk management, Mens et al. (2011) have elaborated the concept of "system robustness" in a similar way to resilience. System robustness has specifically to do with the capacity of a system to absorb disturbances, such as flood waves. This has been defined as "the ability of a river valley or coastal plain to remain functioning under a range of flood waves or storm surges" (Mens 2015:13). In this definition, continued functioning implies either no impact from the flood wave or a limited impact, followed by quick recovery. According to Anderies et al. (2004), the concepts of resilience and robustness are roughly the same if the output being assessed is the continued functioning of a system. The term robustness is considered more appropriate for systems that contain engineering components, such as the flood risk system (Carpenter et al. 2001, Van Staveren and Van Tatenhove 2016). Furthermore, the framing of robustness as a system's absorptive capacity makes it possible to use resilience in its original, narrow meaning (Holling 1996) for flood risk management. This meaning has been specified by de Bruijn (2004:199) as "the ease with which a system recovers from floods." Resilience, in a narrow sense, is one of the characteristics that add to system robustness.

The adoption of a more resilient flood risk strategy will often enhance system robustness. This type of strategy addresses the consequence component of risk, and a key mechanism associated with the strategy is the reduction of flood impacts. Thereby, the classical focus on structural/engineering measures is widened to take into account all possible measures to deal with flood risk, including spatial planning, communication, evacuation, and emergency response. Such more resilient (and integrated)

${ }^{1}$ UNESCO-IHE, Delft, The Netherlands, ${ }^{2}$ Erasmus University Rotterdam, Rotterdam, The Netherlands, ${ }^{3}$ HKV Consultants, Lelystad, The Netherlands, ${ }^{4}$ City of Dordrecht, Dordrecht, The Netherlands 
strategies rely on the self-organizing capacities of the social subsystems and stimulate their capability to learn and adapt. Although a shift toward resilience seems to be desirable in the face of climate change uncertainty, implementing these strategies faces many difficulties across Europe. This is particularly true for countries like the Netherlands or Poland (Hegger et al. 2013), where prevalent governance arrangements are aimed at accommodating flood protection measures. This means that we can expect an institutional misfit when it comes to applying another, more integrated paradigm such as resilient flood risk governance (Lebel et al. 2006).

We analyze the institutional preconditions for the implementation of resilient flood risk strategies. An in-depth study into emerging practices is conducted for the Island of Dordrecht, which is a frontrunner case of resilient flood risk governance in the Netherlands. For this specific case, we aim to identify with an analytical framework, called VGS the following: (1) which set of measures is logically part of a more resilient strategy; (2) what the outcomes of this strategy might be for the social-ecological system; and (3) how likely the strategy is to be implemented under the existing institutional regime, particularly the legal and financing system. These results are then discussed in terms of the enablers and barriers for adopting and implementing a more resilient strategy. Out of this discussion we answer the question whether more generic institutional preconditions can be formulated that enable the implementation of resilient flood risk strategies.

\section{THEORETICAL FRAMEWORK}

Differences between resistant and resilient flood risk strategies Adaptation can be defined as the decision-making process and the set of actions undertaken to maintain the capacity to deal with future change or perturbations to a social-ecological system without undergoing significant changes in function, structural identity, or feedbacks of that system while maintaining the option to develop (Nelson et al. 2007). Within flood risk practice, adaptation often implies that additional strategies and measures are considered to deal with the impacts of sea level rise, higher river discharges and more instances of extreme rainfall. This requires making decisions on whether to adopt a resistant strategy or a more resilient strategy.

Resistant strategies are primarily aimed at managing flood risk through probability reduction. This is achieved by increasing protection levels, for example by strengthening flood defences or making more space for rivers. Increased protection levels, however, do not necessarily make a social-ecological system more robust for extreme flood events, because the impacts of these events are not being managed (Mens and Klijn 2015).

Resilient strategies focus on reducing the impacts of floods through better prevention and preparedness. Prevention of flood impacts can be realized through spatial planning and adaptation of buildings, while preparedness can be improved by developing emergency plans and setting-up insurance schemes. As argued by Mens and Klijn (2015), resilient strategies will increase the robustness of a social-ecological system through preventing those impacts on the system from which recovery is extremely difficult without outside help.

\section{Social-ecological outcomes}

Outcomes describe the intended (and unintended) changes in social-ecological conditions that result from the measures within a strategy (EEA 2015). For example, the outcome of a flood risk strategy could be a reduction in the number of casualties or economic damages. Frameworks for analyzing flood risk strategies are typically based on the concept of risk. Here, risk can be defined as the (probabilistic) expected value of the flood impacts, which equals the area under a "risk curve" (Kaplan and Garrick 1981). A risk curve gives the cumulative probability distribution of the flood impacts. This metric is used either in a cost-effectiveness analysis or in a cost-efficiency analysis to select the preferred flood risk strategy. A cost-effectiveness analysis shows which strategy achieves the required risk level for the lowest investment cost, while a cost-efficiency analysis informs which strategy has the lowest total costs of investments and remaining flood risk (Kind 2014).

Klijn et al. (2015) explain how system robustness can (easily) be included as an additional metric in existing flood risk analyses. This requires drawing up a response curve by plotting the flood impacts as a function of a range of disturbances, like river discharge. As illustrated in Figure 1, the response curve can be considered a risk curve, where the probabilities are replaced by the corresponding river discharge. System robustness can be analyzed in a response curve as the sum of the resistance range and the resilience range (Mens and Klijn 2015). The resistance range is quantified by those discharges that cause no impact to the system. It ends where the impacts become greater than zero. The resilience range is quantified by those discharges that cause limited impact from which the system is able to recover. This range ends where the impacts exceed the recovery threshold, which is the maximum impact from which the system can still recover. The added value of a system robustness analysis is that it supports the exploration of low-probability/high-impact flood events and considerations about whether these impacts are societally acceptable (Mens and Klijn 2015).

Fig. 1. Response curve of a flood risk system (adapted from Mens et al. 2011).

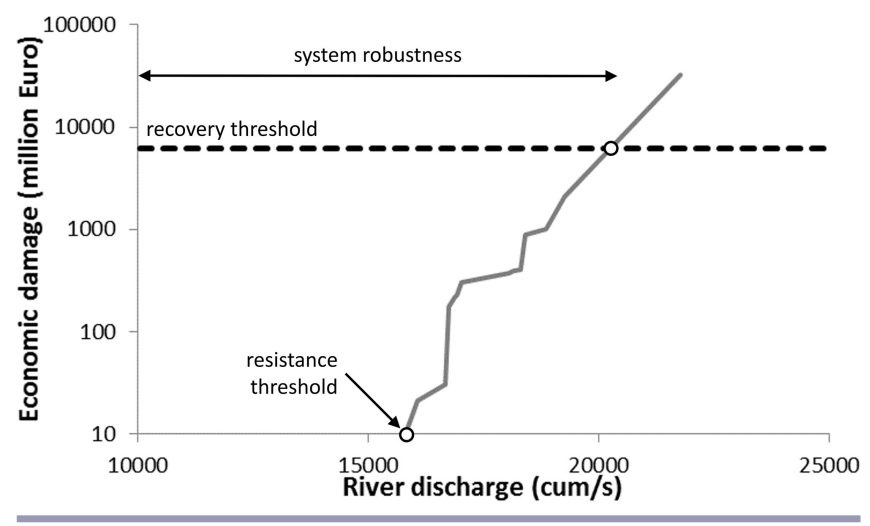

\section{Institutional feasibility}

Institutional feasibility describes the extent to which a strategy is likely to be implemented under the existing institutional regime (Gupta et al. 2007). Many studies emphasize that implementing resilient strategies to deal with flood risk is hindered by multiple 
institutional gaps and barriers (Matczak et al. 2015). Current flood risk governance arrangements are not often designed to accommodate more resilient or integrated strategies. A commonly mentioned problem has to do with normative principles that underlie the dominant flood risk paradigm. Within an institutional regime that is based upon principles of flood protection, and thus resistance against floods, legal standards reflect the idea that the government is solely responsible for organizing flood protection. A transition toward more resilient flood risk strategies implies that the focus changes from protection toward mitigating risks, which implies that the distribution of responsibilities also changes. A second problem that is evident from literature on climate change adaptation is the misfit with current institutional rules and arrangements (Biesbroek 2014). On the one hand innovative strategies can be faced with an institutional void: the necessary rules are not available and have to be developed. On the other hand there is institutional fragmentation: the existing rules within specific policy domains do not necessarily match with each other, which makes it difficult to apply strategies that are integrated and/or address multiple objectives. Another barrier relates to the fact that resilient flood risk strategies presuppose local or regional tailor-made responses that are based upon unique combinations of measures with regard to prevention, protection, and preparedness. It is questionable whether the current institutional regime allows for such tailormade responses. Resilient strategies ask for institutional flexibility, and policy instruments that enable these responses. Finally, resilient flood risk strategies are often based upon a holistic system perspective. The focus is upon designing integrated strategies that acknowledge the multiplicity of social-ecological subsystems and the interaction and feedback loops within these systems. However, such strategies do not fit within the administrative boundaries of governmental agencies. That means that implementing resilient strategies requires auxiliary arrangements or institutional suppleness (Van Buuren et al. 2015).

\section{METHODS}

\section{VGS analytical framework}

The flood risk strategies were outlined and assessed with the VGS analytical framework, which was developed by the Dutch Delta Programme (Delta Commissioner 2014). The VGS is a tool to provide decision makers with objective information about flood risk strategies that enables them to take informed decisions. Furthermore, the VGS makes explicit what information is considered relevant to compare and decide on the flood risk strategies. The VGS characterizes flood risk strategies based on four main criteria: effectiveness, side-effects, cost-efficiency, and institutional feasibility. These criteria were partly informed by a social cost benefit analysis, in the sense that the most relevant cost and benefit categories have been incorporated. Yet the VGS takes a broader view and also includes criteria that are not part of such an analysis, like the institutional feasibility of a strategy.

The first main criterion (effectiveness) determines the extent to which a strategy is effective in meeting the objectives for flood risk management. This relates to the primary effects being intended with the strategy, such as reducing flood risk and enhancing system robustness. In addition, a particular strategy will have secondary effects, which together form the second main criterion (side-effects). This includes positive as well as negative side-effects. The latter could be unintended, but are nevertheless linked to the strategy. An example of a positive side-effect is the prospect of ecosystem restoration from spatial measures, and a negative side-effect is the loss of cultural heritage due to dike strengthening. The third main criterion (cost-efficiency) relates to the total economic cost of a strategy, which is the sum of the investments and the remaining flood risk. The last main criterion (institutional feasibility) determines the extent to which the strategy is supported by the existing institutional regime. For each main criterion, a set of subcriteria has been selected that are relevant and distinctive for the Island of Dordrecht. Together these criteria provide a case-specific perspective on the VGS (Table $1)$.

Table 1. VGS analytical framework.

\begin{tabular}{ll}
\hline \hline Main criteria & Case-specific criteria \\
\hline Effectiveness & Reduction of flood risk \\
& $\begin{array}{l}\text { Enhancement of system robustness } \\
\text { Preservation of cultural heritage } \\
\text { Side-effects }\end{array}$ \\
& $\begin{array}{l}\text { Ecosystem restoration } \\
\text { Minimization of total economic } \\
\text { Cost-efficiency }\end{array}$ \\
cost \\
Institutional feasibility \\
& $\begin{array}{l}\text { Feasibility under the legal system } \\
\text { Feasibility under the financing } \\
\text { system }\end{array}$ \\
\hline
\end{tabular}

The VGS assesses the flood risk strategies based on a scorecard approach. In the VGS, the scoring takes place compared with a reference strategy (in this case, the resistant flood risk strategy). The extent to which a strategy meets a criterion is scored as follows: 5 (strong positive effect), 4 (positive effect), 3 (neutral), 2 (negative effect) and 1 (strong negative effect). As the scoring takes place compared with the reference strategy, the effects of the latter strategy are scored as 3 for each criterion. The VGS assigns no weights to the various criteria. This means that it indicates, for example, whether a positive score on cost-efficiency should be considered more or less heavily than a negative score on side effects. Neither does it rank the flood risk strategies, by indicating whether one strategy is better or worse than another.

\section{Case study: the Island of Dordrecht}

We applied the VGS framework to a proposed outline resilient strategy for the Island of Dordrecht to analyze its outcomes and institutional feasibility in comparison with a resistant strategy. The Island of Dordrecht is located in the transitional area of the Rhine-Meuse delta, where the threat of flooding arises from the interplay between the sea and the rivers. The island has both a protected part, which is protected by a single series of primary flood defences, and an unprotected part. The north of the island is an urban and industrial area, and the south is mostly used for agriculture. The governance structure is relatively simple: one municipality, one regional water authority, and one regional emergency management authority are each responsible for one aspect of flood risk management. These are, respectively: prevention through spatial planning, protection by flood defences, and preparedness for emergency response. This means that the Island of Dordrecht provides a contemporary example of a delta city threatened by flooding. 
The Island of Dordrecht is a pilot study of the Dutch Delta Programme on resilient flood risk governance, with a specific focus on "smart combinations" of measures. The concept, or rather legal instrument, of a smart combination was introduced in the Delta Decision on Flood Risk Management to provide for the possibility, in specific cases, to replace flood protection measures with measures involving prevention and preparedness (Delta Commissioner 2014). The local/regional authorities and central government jointly commissioned the pilot study to gain practical experience with the application of smart combinations. This study involved the elaboration of a coherent set of measures that address all aspects of flood risk management and together make up the resilient strategy. These measures are outlined below, and visualized in Figure 2:

Fig. 2. Visualization of the resilient strategy (courtesy: De Urbanisten). This strategy consists of vertical evacuation to higher floors and shelter locations (above), compartmentalization by restoring the regional flood defences (middle), and an adjustment of the legal standard for the primary flood defences (below).

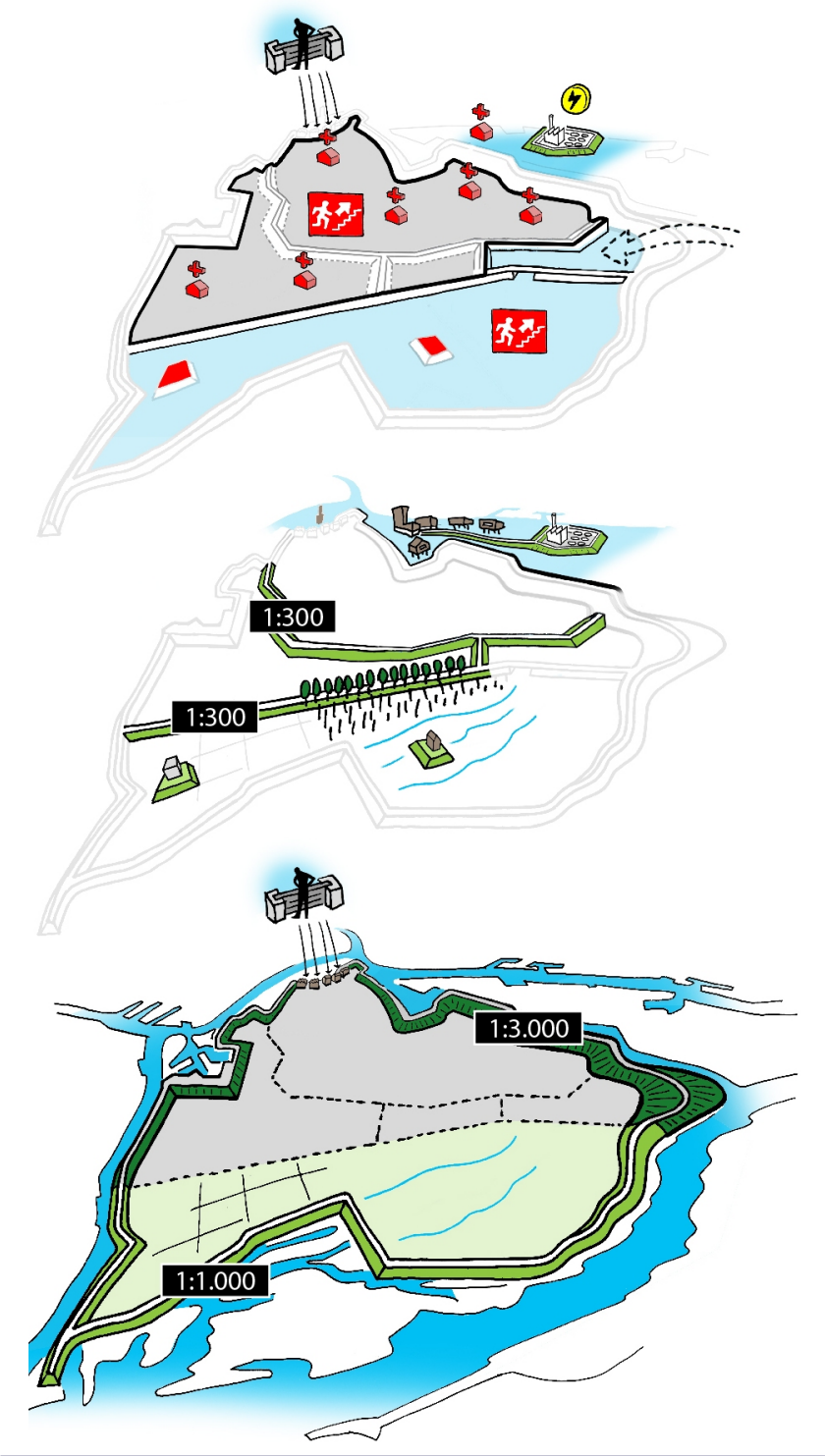

- Prevention: The area subject to flooding can be reduced by splitting up the Island into smaller portions, which is called compartmentalization (Klijn et al. 2010). Compartmentalization is achieved by strengthening, and partially removing, regional flood defences to keep water away from the urban area in the case of a river-dominated flood event (Fig. 3). This would contribute to the reduction of the number of casualties and damage, because the urban area is the most vulnerable area to flooding.

- Protection: Given the positive effects of compartmentalization on casualties and damage reduction, the primary flood defences would require less improvement. This is because the flood risk standard will be achieved through a combination of protection (by the primary flood defences) and prevention (using compartmentalization). Here, the legal instrument of a smart combination makes it possible to adjust the legal standard pertaining to the primary flood defences.

- Preparedness: The number of casualties can be further reduced by enhancing institutional and community preparedness; supplementary to better prevention and protection. This means that the necessary preconditions for vertical evacuation, such as to higher floors or dry locations (Kolen and Helsloot 2012), have to be specified and realized. These include determining the availability of shelter locations, informing the public about evacuation options, estimating the effectiveness of evacuation, and making agreements on the continued operation of IT and utility systems as the flood threat increases.

Fig. 3. Map of the Island of Dordrecht, with the predicted water depths in the urban area for a river-dominated flood event (courtesy: De Urbanisten).

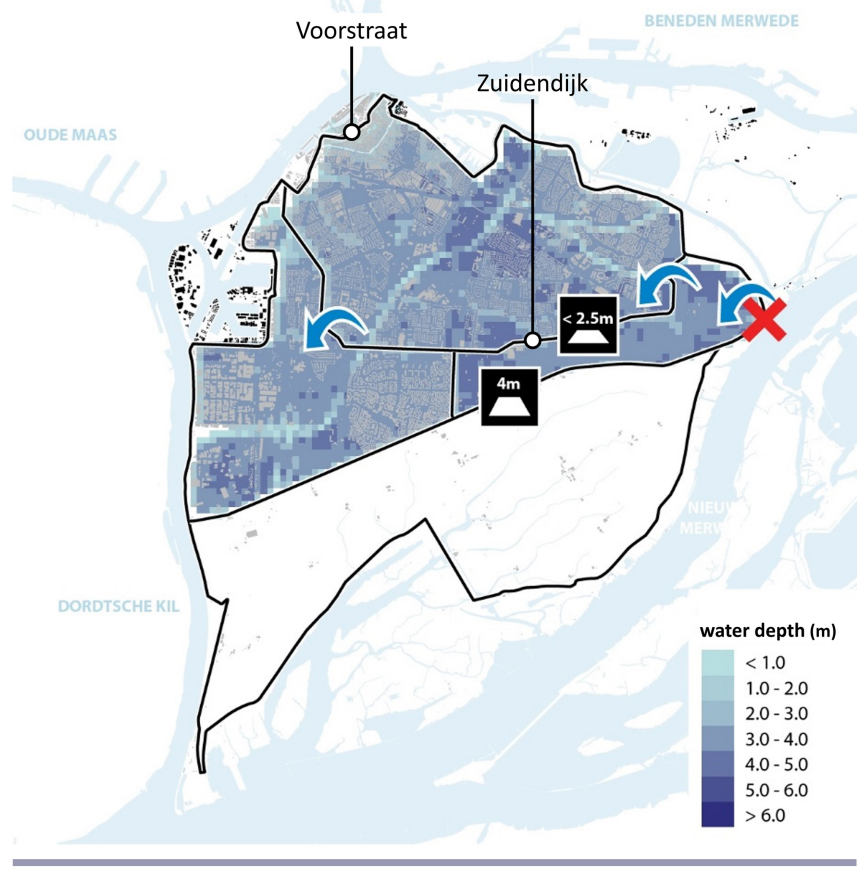


The resilient strategy is compared with a resistant strategy, which is a continuation of the current (reference) flood risk strategy. The resistant strategy involves managing flood risk through protection by primary flood defences only. No measures are being taken to improve prevention and preparedness. As such, the spatial layout of the regional flood defences remains the same, although these flood defences may no longer be adversely affected by spatial developments. The evacuation strategy for the island also remains the same, which is directed toward a preventive, organized evacuation.

\section{Data collection and analysis}

The flood risk strategies were quantitatively assessed for effectiveness and cost-efficiency, as summarized here:

- The changes in flood risk were calculated for different risk metrics: local individual risk (probability of dying of an individual at a certain location per year, independent of the presence of the individual during the flood at this location), loss-of-life risk (expected value of the number of fatalities in individuals per year), economic risk (expected value of the economic damage in Euros per year), societal risk or FN-curve (graph of cumulative distribution of the number of fatalities) and FS-curves (graph of cumulative distribution of the number of economic damage). These risk metrics were determined for the year 2050, taking into account the impacts of climate change and social-economic growth on flood risk. The flood risk analysis was based on the updated flood protection standards as derived in the Delta Programme (Van Alphen 2015), the flood scenarios as developed for the existing spatial layout as well as for different spatial measures (Vermeulen et al. 2015), and the expected consequences for each flood scenario. The consequences were calculated with the HIS Damage and Fatalities Module (Kok et al. 2005), which is the standard software in the Netherlands to assess the economic damage and number of fatalities in case of flooding. The possibilities of preventive evacuation have been estimated and incorporated into these calculations (Kolen et al. 2013). The FN-curve shows the probability that $1,10,100$, or 1000 fatalities will occur as a result of flooding. The FS-curves expresses the equivalent for economic damage: 1, 10, 100, 1000 million Euro.

- The changes in system robustness were analyzed by quantifying the system's ability to recover from the flood impacts, with or without financial aid. For the system robustness analysis, the recovery threshold was set at $5 \%$ of the regional gross domestic product (GDP) and the national GDP, to indicate respectively whether financial aid of other Dutch regions or financial aid from other countries is needed (Mens and Klijn 2015).

- The total costs to implement a strategy were determined by the sum of the investment cost and the present value of the expected damage.

The Delphi method was used to qualitatively assess the sideeffects. This is a structured method where a group of stakeholders (with various backgrounds) aim to reach consensus in a cyclic process. This method was undertaken as follows. In a first round, each group member shared and explained their assessment of the side-effects of the resilient strategy when compared with the resistant strategy. This was limited to scoring the side-effects of the resilient strategy with the scoring function proposed for the VGS. In the following round(s), the group members considered a revision of their own assessment (that is, scores) by learning from each other's arguments. The scores for cultural heritage preservation related to the effects on the scenic and cultural heritage values, according to the stakeholders' perception. The Island of Dordrecht is an impoldered landscape (reclaimed land after the Elizabeth flood of 1421) with old, regional flood defences that characterize the landscape. These regional flood defences are partly covered by ribbon development and rows of trees, which represent identifiable scenic and cultural heritage values (that might be affected by dike strengthening). The scores for ecosystem restoration related to the effects on the ecological values of the aquatic and terrestrial ecosystem. This critically depended on the potential to restore the ecosystem of the Biesbosch (while implementing flood risk measures). The Biesbosch is Europe's largest fresh water tidal area and is part of the EU-wide network of nature conservation areas, called the Natura 2000 network.

The institutional feasibility has to do with the degree to which measures fit with the current rules, procedures, and routines of the involved governmental agencies. It is about the question to what extent the current institutional provisions enable the implementation of a resilient flood risk strategy and which institutional inadequacies there are that are likely to hamper implementation. The institutional feasibility was quantitatively assessed through in-depth interviews with representatives from the governmental agencies involved. These representatives were asked to reflect (using the scoring function for the VGS) upon the resilient strategy and how well it fits within the current legal framework and financing system. In the interviews, we asked respondents to elaborate on which problems the resilient flood risk strategy will encounter when measures have to be implemented. Are there provisions to deviate from the standard procedure of dike strengthening? Are there legal instruments to secure the measures that constitute a resilient strategy? Do the current budget rules allow for financing spatial measures that (partly) replace a dike improvement? We also relied upon an earlier study conducted into implementation requirements for resilient flood risk management (Van Buuren and Ellen 2014). This study investigated all relevant components of the current flood risk regime with help of the four levels of institutional prescriptions of Williamson (1999) and confronted these with the requirements that a more resilient approach poses.

\section{RESULTS}

\section{Social-ecological outcomes of the resilient strategy}

We found that the resilient strategy fulfils the requirements of the flood risk standards until 2050. The basic safety level will be guaranteed, which requires that the local individual risk should not exceed $1 / 100.000$ per year. The resilient strategy was a more effective strategy to decrease the probability of a large number of fatalities per year, and therefore to reduce the relative contribution to the national societal risk, than the resistant strategy (societal risk expressed in Fig. 4). As an example, Figure 4 shows that the resilient strategy results in a decrease of the annual exceedance 
probability of a group of 100 fatalities to less than $1 / 50.000$ per year (caused by a strong decrease of the number of fatalities by most of the individual flood scenarios in the resilient strategy); compared with the resistant strategy this is a 10 times less frequent annual exceedance. It also reduces the economic risk more effectively (Fig. 5). The present value of the economic risk is about $€ 110$ million for the resilient strategy, compared with about $€ 155$ million for the resistant strategy. The present value of the economic risk is the sum of the yearly economic risk between 2015 and 2050. The present value of the benefits of the implementation of the resilient strategy over this period would be $€ 45$ million ( $€ 155$ million minus $€ 110$ million).

Fig. 4. Societal risk for resilient strategy (red line) and the resistant strategy (grey line).

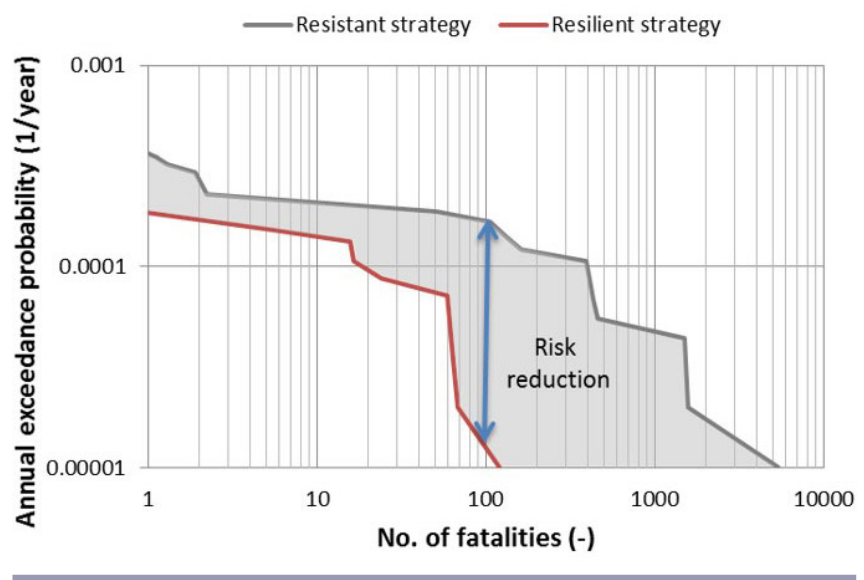

Fig. 5. Economic risk for the resilient strategy (red line) and the resistant strategy (grey line), with the recovery threshold of 5\% of regional GDP (blue line) and national GDP (green line).

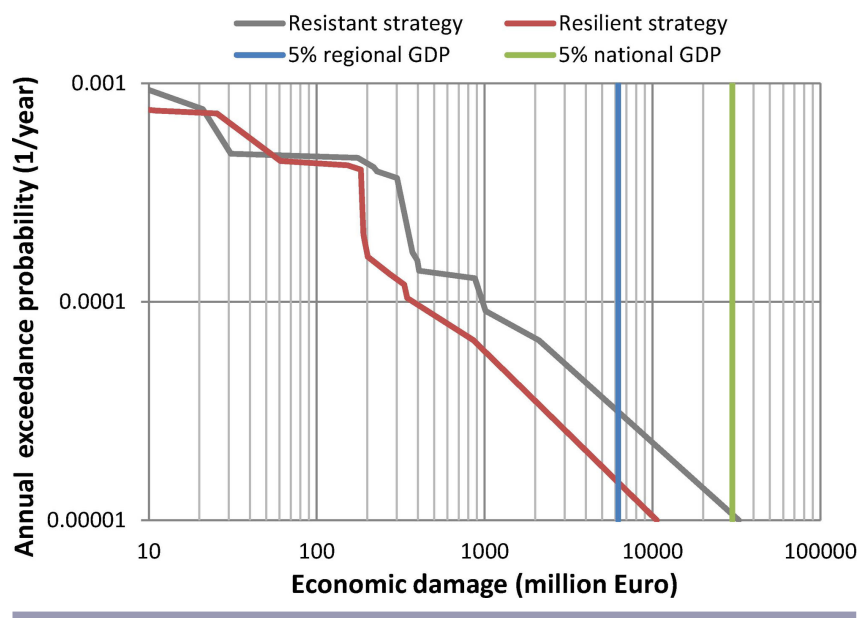

The system robustness is enhanced by the resilient strategy. This is because the economic damage for the more extreme flood scenarios is considerably smaller compared with the resistant strategy. It can be observed from Figure 5 that the resilient strategy is not dependent on financial support from other countries to recover the Island of Dordrecht because the response curve is below the recovery threshold.

The resilient strategy has both a positive and negative effect on the preservation of cultural heritage, compared with the resistant strategy. The positive effect arises from the adjustment of the legal standard for the primary flood defences. This measure makes it possible to postpone the dike improvement along the Voorstraat by 50 years until 2100 and, therefore, to prevent the degradation of the historic buildings on top of this dike. Yet, the strengthening of the regional flood defences will negatively influence the scenic and cultural heritage values. This is because a dike improvement along the Zuidendijk will likely affect the ribbon development and the rows of trees (Fig. 3).

The ecosystem restoration project for the Biesbosch is positively influenced by the resilient strategy. It aims to restore the ecological connectivity in the northern part of the Biesbosch by realizing a blue-green corridor. The partial removal of a regional flood defence, as proposed for the resilient strategy, provides an opportunity to further enhance the new blue-green corridor. This is because the creation of an opening in the regional flood defences will make it more accessible for small mammals, such as the beaver, otter, and vole (Fig. 6).

Fig. 6. Proposed opening in the regional flood defence, which provides the opportunity to restore the ecological connectivity (courtesy: De Urbanisten)

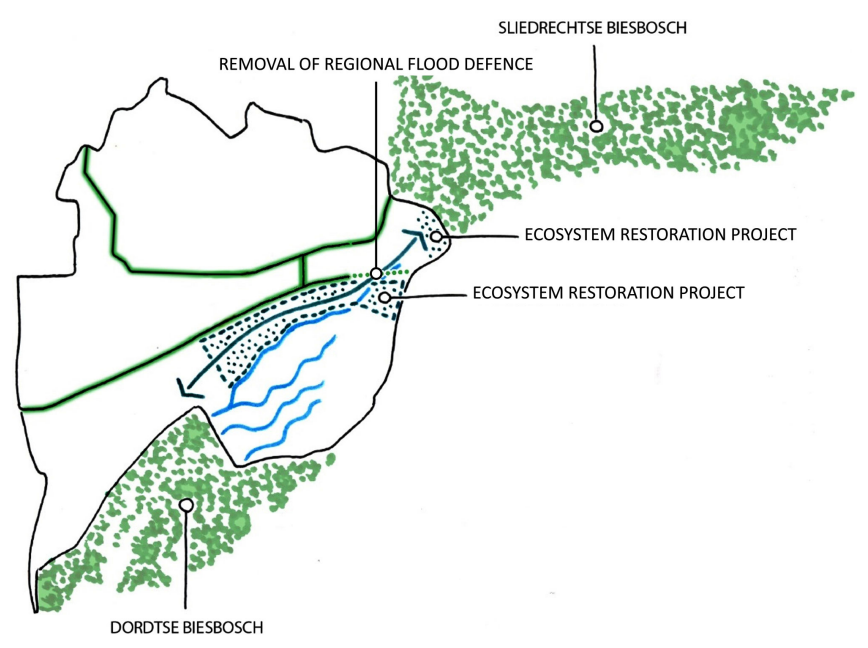

The total economic costs of the resilient strategy are slightly lower than for the resistant strategy: about $€ 180$ million compared with some $€ 215$ million (Table 2). This comprises both the investments in flood risk management and the remaining flood risk. The investment costs for both strategies are roughly the same, although the attribution to the major cost categories differs. With the resilient strategy, a large part of the investments will be in the regional flood defences (compartmentalization) and preparedness for vertical evacuation, next to strengthening the primary flood defence system. However, there is significant uncertainty about the investments in regional flood defences because of a lack of geophysical data. 
Table 2. Total costs for the resilient and resistant strategies.

\begin{tabular}{lcc}
\hline \hline Total costs (million $€$ ) & $\begin{array}{c}\text { Resilient } \\
\text { strategy }\end{array}$ & $\begin{array}{c}\text { Resistant } \\
\text { strategy }\end{array}$ \\
\hline $\begin{array}{l}\text { Present value of the economic } \\
\text { risk }\end{array}$ & 112 & 153 \\
$\begin{array}{l}\text { Investments in primary flood } \\
\text { defences }\end{array}$ & 28 & 59 \\
$\begin{array}{l}\text { Investments in regional flood } \\
\text { defences }\end{array}$ & 17 & 3 \\
$\begin{array}{l}\text { Investments in vertical } \\
\text { evacuation }\end{array}$ & 20 & 0 \\
Total economic cost & \pm 180 & \pm 215 \\
\hline
\end{tabular}

\section{Institutional feasibility of the resilient strategy}

The implementation of the measures within the resilient strategy is strongly dependent on the availability of tailor-made governance arrangements. With respect to this, it is necessary to make a distinction between smart combinations (with measures involving prevention and preparedness) and supplementary measures (involving prevention and preparedness). For the smart combination with compartmentalization of the Island, an administrative agreement is required with agreements on the necessary measures on the regional flood defences (including a legal standard for maximum failure probability) and the safeguarding thereof over the longer term. The latter requires a clear elaboration of tasks, responsibilities, and financing. Such a smart combination also requires the minister's approval, because the required risk level is achieved through a combination of measures instead of flood protection only.

There are no legal requirements, however, for the measures that are being proposed to improve preparedness for vertical evacuation. This is because these measures are supplementary to flood protection. The effectiveness of these measures has to be safeguarded by the decentralized execution of emergency management, including risk communication. This should be supported by easily available risk-related information, so that the regional emergency management authority can take rapid decisions before and during a flood event. Next to increased decentralized responsibilities, the general public also has to take a greater role and responsibility in emergency management. The authorities can facilitate this role by providing the inhabitants with clear and specific information about possible flood events and how to act in case of an emergency. Such a communication strategy will raise their risk awareness, and thereby likely contribute to improved preparedness (Maidl and Buchecker 2015). A higher risk awareness could, in turn, contribute to (the continued) political support for implementation of the resilient strategy. From our interview round we can conclude that many of the existing procedures of the participating authorities can be used to implement the resilient strategy. The Water Board can apply existing instruments (in Dutch: legger, keur) to give spatial objects a formal function. The province can give secondary dikes a formal status as partitioning dikes. The safety region can include many measures in its regional emergency plan. And the municipality can anchor measures in its spatial zoning plan. Organizing implementation is thus much more a matter of creativity and commitment to align these existing procedures to the shared vision than to "fight against" institutional rigidity or a need to fill an institutional vacuum.

The measures within the resilient strategy are overall more challenging to finance from the Delta Fund, which is the main resource for investing in flood risk management. This is because this fund has specifically been earmarked for flood protection. Under certain conditions, however, resources can be made available from the Delta Fund for the implementation of a smart combination of measures. These conditions are that the resources are comparable to the cost savings on improving the primary flood defence system; that the resources are spent on hydraulic measures; and that an administrative agreement on the smart combination is in place. Because the smart combination with compartmentalization complies with the aforementioned conditions, the investments in the regional flood defences can be financed from the Delta Fund. There is, however, no straightforward mechanism for financing the investments in preparedness for vertical evacuation. These measures will have to be realized by mainstreaming with spatial (re)developments and investments in infrastructure and buildings (Gersonius et al. 2012). Their financial feasibility, therefore, strongly depends on the opportunities to connect with other developments and investments. For the Island of Dordrecht, key relevant opportunities include the following: taking advantage of the renovation of public buildings to realize shelter locations; taking advantage of the renovation of a provincial road to realize an elevated evacuation route; and using the regional implementation of the EU SEVESO III Directive (on the control of major-accident hazards) to improve the individual protection of critical infrastructure sites.

\section{DISCUSSION}

Identified enablers and barriers for the Island of Dordrecht The results of the VGS analysis are summarized in Figure 7, which is a radar diagram. The purpose of this diagram is to show, in a graphical way, how the resilient strategy scores in comparison with the resistant strategy. In line with the scorecard approach, a score is shown in green in case of an expected positive effect and in red in case of an expected negative effect.

The radar diagram indicates that the adoption of a resilient strategy has several positive effects for the Island of Dordrecht. This added value is not only substantial when it comes to the primary effects intended with the strategy, such as reducing risk and enhancing system robustness. But the added value lies also within the social and ecological domains. Positive side effects of the resilient strategy include the restoration of the Biesbosch ecosystem and the preservation of the historic buildings along the Voorstraat. The resilient strategy, however, has a negative effect on the preservation of the ribbon development and the rows of trees along the Zuidendijk. 
Fig. 7. Radar diagram of the effects of the resilient strategy, when compared with the resistant strategy. The scoring is as follows: 5 (strong positive effect), 4 (positive effect), 3 (neutral), 2 (negative effect), and 1 (strong negative effect).

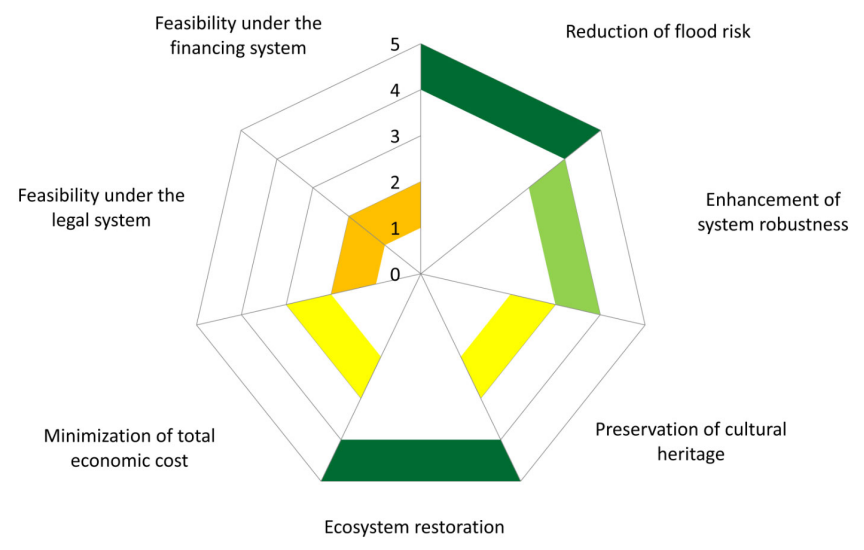

It is clear that the resilient strategy is more difficult to implement, when compared with the resistant strategy. The implementation is difficult for three reasons. First, it is difficult to find a suitable legal arrangement that gives the competent water authorities enough confidence in the long-term viability of the measures. These emphasize the importance of clarity about the new distribution of responsibilities and demand that these responsibilities are legally anchored and translated into binding agreements. Safeguarding that the measures will remain effective in the long term and will not fail in case of an emergency, is seen as conditional for approving the adjustment of the legal standard for the primary flood defences. Second, it is difficult to organize the financial resources necessary for implementing the resilient strategy. In contrast to the resistant strategy, resources have to be reallocated before the strategy can be implemented, and in some instances, e.g., compartmentalization, they should be brought forward in time. Also, authorities like the municipality and regional emergency management authority have to make additional resources available. These resources are not automatically available for flood risk management, which is not part of the formal tasks of these authorities. A third difficulty for implementation is the effort that is required to organize and safeguard sufficient commitment of all relevant actors who have to contribute to the realization of the resilient strategy, now or in the (near) future. The realization of the strategy depends upon the sustained collaboration between and continuous effort of many actors who each have their own agenda and procedures. It is difficult to find a sufficiently binding and flexible governance arrangement that enables a promising durable implementation pathway, giving the regional water authority enough confidence in the ultimate realization.

Summing up the results of the VGS analysis, the resilient strategy scores positive on three, neutral on two, and negative on two of the case-specific criteria. As such, the question will arise how to decide if the resilient strategy is preferable over the resistant strategy. Although this question is very relevant, the VGS analytical framework intentionally does not set out to answer it.
Rather, the judgment on the selection of a preferred strategy is left to the responsible decision makers. The VGS merely aims to provide, in a structured way, the information that decision makers need to make a sound judgment. In the case of Dordrecht, the responsible decision makers have judged the resilient strategy as a promising alternative for the resistant strategy. Furthermore, they have asked for a follow-up to the pilot study that should further substantiate the effects of the resilient strategy, as needed to select the preferred strategy. The detailed assessment mainly concerns the criteria minimization of total economic cost (related to the uncertainty about the investments in regional flood defences) and feasibility under the financing system (which is a particularly relevant criterion for the regional water authority).

\section{Institutional preconditions for implementation?}

The Dordrecht case shows that it is possible to develop a promising resilient flood risk strategy, especially when this is carried out in a relatively safe context like a pilot study, which is somewhat overshadowed by the formal structures and distanced from the standard operating procedures of the participating authorities. At the same time, this context also hinders its implementation. In the theoretical framework, we have distinguished four issues regarding governance arrangements that hinder the implementation of resilient strategies. All these issues play a role when it comes to the identified implementation barriers:

- Misfit with existing normative principles;

- Misfit with current institutional rules and arrangements;

- Lack of institutional flexibility, not allowing tailor-made responses;

- System fragmentation.

In the Dordrecht case, the resilient strategy does not significantly contradict current normative principles about flood risk. It is unusual that there is local support for a strategy that places less emphasis on flood protection and more on impact reduction. Issues of equity and social justice (between the northern and the southern part of the island) have until now not been raised by local politicians. By developing and communicating a definitive perspective on how to act in emergency situations, the authorities were able to avoid scepticism and to generate enthusiasm for the vision of a self-reliant island. The misfit with normative principles is much more of a misfit of interpretation between different authorities. This is especially the case when it comes to accountability: a resilient strategy makes it (in the perception of the regional water authority and central government) more difficult to answer the question who is accountable in case of a flood event, compared with a resistant strategy. For the other authorities, this is mostly a matter of properly formalizing what is agreed upon.

There is a serious misfit of the resilient strategy with the current institutional rules and arrangements, which are entirely aimed at accommodating flood protection measures. This explains why the regional water authority and central government emphasize the importance of legal safeguarding of the measures. As such, there is a need for various auxiliary arrangements to enable the implementation of the strategy. This strategy in fact has to be implemented in an institutional vacuum, in which all necessary 
rules have to be developed from scratch and many existing rules have to be adjusted or complemented, for example, when it comes to the legal safeguarding of the compartmentalization.

The issue of institutional (in)flexibility resonates in the doubts actors have that they will be able to reach a convincing administrative agreement that will enable the collaborative implementation of the strategy. The resilient strategy can only be realized when all governmental agencies contribute over the long term to its implementation, and when it can be implemented in an incremental and adaptive manner, e.g., when an adaptation opportunity arises. This requirement contrasts sharply with the existing situation in which one competent authority is responsible for flood protection and is accustomed to implementing singular measures that suffice for 50 years. This system is highly effective, but inflexible to change. An alternative, more collaborative and polycentric system increases flexibility (Pahl-Wostl 2009), but has no proven record of effectiveness.

Finally, system fragmentation is a significant barrier for implementing the resilient strategy. The lack of connective capacity between the different authorities at different levels and the rather strong boundaries between these, makes it difficult to make the step from a shared vision and strategy toward a joint implementation plan with explicit formal commitment. Jointly developing a regional, integrated flood risk strategy, presupposes the use of a problem definition that departs from the regional level (Huitema et al. 2009). Acting on this level necessitates sustained collaboration between very different governmental agencies with their own jurisdictions and boundary judgments, which is anything but self-evident.

There are also no generic institutional design parameters that have to be applied for implementing resilient flood risk strategies. Even in the current institutional regime (focused on flood protection), it is possible, although difficult and with many transaction costs, to find a way of implementing a resilient strategy. The more general institutional precondition has to do with the political willingness to allow for other, more collaborative and explorative ways of working and experimentation, and to enable a more flexible use of current principles and rules (Folke et al. 2005). Implementing resilient strategies in the Dutch context is thus more a matter of leadership that sanctions a pragmatic use of institutional provisions than of redesigning those.

\section{CONCLUSION}

An emerging trend in flood risk practice is to include system robustness enhancement as an additional objective, next to risk reduction. This supports considerations on whether a socialecological system is able to remain functioning under a wide range of flood waves, or whether it might be affected beyond recovery. Although some scholars have analyzed flood risk strategies from both a risk and a robustness perspective, these strategies have so far been rather simplistic in character (Klijn et al. 2015). Furthermore, such studies have been largely executed outside of practicable flood risk practice and therefore have not considered the institutional feasibility of strategies. Yet, it has been observed that resilient flood risk strategies are, in many cases, more difficult to implement than resistant strategies. This is especially the case when the current institutional regime is aimed at facilitating resistant strategies.
In this article, we have outlined a comprehensive resilient strategy for the Island of Dordrecht, and analyzed its various outcomes and institutional feasibility. The resilient strategy has entailed improving preparedness for vertical evacuation, restoring the regional flood defences, and lowering the legal standard for the primary flood defences. We have demonstrated the resilient strategy is more effective and cost-efficient than its resistant counterpart, while at the same time delivering substantial cobenefits. This comes at a trade-off, however, of reduced feasibility of the strategy under the institutional regime. By drawing from governance literature, we have identified several misfits between the resilience strategy and the current institutional regime. However, as we have observed, addressing these misfits has not so much to do with redesigning the current regime, but more with enabling another way of interpreting and applying the regime. The transition in the Netherlands toward this new paradigm of flood risk management is currently in its infancy (Van Buuren and Ellen 2014). In this phase, institutional redesign is neither very feasible nor productive because we do not know how the transition will evolve. Much more important is facilitating a process of institutional experimentation (by exploring new arrangements and procedures) and exploiting the results to support the process of institutional learning and gradual institutional change.

Although the Dutch flood risk tradition is quite unique because of strong focus on flood protection, the difficulties of changing the dominant path within flood risk management are much more generic. This is similar in, for example, Germany (Garrelts and Lange 2011), Hungary (Sendzimir et al. 2010), and England (Potter 2012). Therefore, realizing a paradigm shift toward more resilient flood risk management can only succeed when it is accompanied by an institutional transformation process. Such a process cannot be planned, but as we can learn from this case and what is substantiated by literature, this can be supported by organizing pilots or experiments (Farrelly and Brown 2011) and by putting effort into a process of joint, social learning (PahlWostl et al. 2007).

Responses to this article can be read online at: http://www.ecologyandsociety.org/issues/responses. $\mathrm{php} / 8752$

\section{Acknowledgments:}

The authors acknowledge the support by NWO, the Dutch Organization for Scientific Research, under grant number W.01.65.339.00. We also thank Prof. Richard Ashley for improving the readability of this article and two anonymous reviewers for their helpful and constructive comments.

\section{LITERATURE CITED}

Adger, W. N., T. P. Hughes, C. Folke, S. R. Carpenter, and J. Rockström. 2005. Social-ecological resilience to coastal disasters. Science 309:1036-1039. http://dx.doi.org/10.1126/science.1112122

Anderies, J. M., M. A. Janssen, and E. Ostrom. 2004. A framework to analyze the robustness of social-ecological systems from an 
institutional perspective. Ecology and Society 9(1):18. [online] URL: http://www.ecologyandsociety.org/vol9/iss1/art18/

Biesbroek, G. 2014. Challenging barriers in the governance of climate change adaptation. Dissertation. Wageningen University, Wageningen, The Netherlands.

Brand, F. S., and K. Jax. 2007. Focusing the meaning(s) of resilience: resilience as a descriptive concept and a boundary object. Ecology and Society 12(1):23. [online] URL: http://www. ecologyandsociety.org/vol12/iss1/art23/

Carpenter, S., B. Walker, J. M. Anderies, and N. Abel. 2001. From metaphor to measurement: resilience of what to what? Ecosystems 4:765-781. http://dx.doi.org/10.1007/s10021-001-0045-9

de Bruijn, K. M. 2004. Resilience indicators for flood risk management systems of lowland rivers. International Journal of River Basin Management 2:199-210. http://dx.doi. org/10.1080/15715124.2004.9635232

Delta Commissioner. 2014. Delta Programme 2015. Working on the Delta. The decisions to keep the Netherlands safe and liveable. [English version]. Ministry of Infrastructure and the Environment, Ministry of Economic Affairs. Dutch National Government, The Hague, The Netherlands.

European Commission (EC). 2013a. Multiannual financial framework 2014-2020 and EU budget 2014: the figures. Publications Office of the European Union, Luxembourg. http:// dx.doi.org/10.2761/9592

European Commission (EC). 2013b. Communication from the Commission to the European Parliament, the Council, the European Economic and Social Committee and the Committee of the Regions, An EU Strategy on Adaptation to Climate Change. COM (2013) 2016 final. EC, Brussels, Belgium. [online] URL: http://eur-lex. europa.eu/legal-content/EN/TXT/PDF/?uri=CELEX:52013DC$\underline{0216 \& \text { from }=\mathrm{EN}}$

European Environment Agency (EEA). 2015. National monitoring, reporting and evaluation of climate change adaptation in Europe. EEA, Copenhagen, Denmark. http://dx.doi. org/10.2800/629559

Farrelly, M., and R. Brown. 2011. Rethinking urban water management: experimentation as a way forward? Global Environmental Change 21(2):721-732. http://dx.doi.org/10.1016/ j.gloenvcha.2011.01.007

Folke, C., S. R. Carpenter, B. Walker, M. Scheffer, T. Chapin, and J. Rockström. 2010. Resilience thinking: integrating resilience, adaptability and transformability. Ecology and Society 15(4):20. [online] URL: http://www.ecologyandsociety.org/vol15/iss4/ art20/

Folke, C., T. Hahn, P. Olsson, and J. Norberg. 2005. Adaptive governance of social-ecological systems. Annual Review of Environment and Resources 30:441-473. http://dx.doi.org/10.1146/ annurev.energy.30.050504.144511

Garrelts, H., and H. Lange. 2011. Path dependencies and path change in complex fields of action: climate adaptation policies in Germany in the realm of flood risk management. Ambio 40 (2):200-209. http://dx.doi.org/10.1007/s13280-010-0131-3
Gersonius, B., F. Nasruddin, R. Ashley, A. Jeuken, A. Pathirana, and C. Zevenbergen. 2012. Developing the evidence base for mainstreaming adaptation of stormwater systems to climate change. Water Research 46:6824-6835. http://dx.doi.org/10.1016/ j.watres.2012.03.060

Gupta, S., D. A. Tirpak, N. Burger, J. Gupta, N. Höhne, A. I. Boncheva, G. M. Kanoan, C. Kolstad, J. A. Kruger, A. Michaelowa, S. Murase, J. Pershing, T. Saijo, and A. Sari. 2007. Policies, instruments and co-operative arrangements. Chapter 13 in B. Metz, O. R. Davidson, P. R. Bosch, R. Dave, L. A. Meyer, editors. Climate change 2007: mitigation. Contribution of Working Group III to the Fourth Assessment Report of the Intergovernmental Panel on Climate Change. Cambridge University Press, Cambridge, UK.

Hegger, D., C. Green, P. Driessen, M. Bakker, C. Dieperink, A. Crabbé, K. Deketelaere, B. Delvaux, C. Suykens, and J.-C. Beyers. 2013. Floodrisk management in Europe: similarities and differences between the STAR-FLOOD consortium countries. STAR-FLOOD Consortium, Utrecht, The Netherlands.

Holling, C. 1996. Engineering resilience versus ecological resilience. Pages 31-43 in P. C. Schulze, editor. Engineering within ecological constraints. National Academy Press, Washington, D. C., USA.

Huitema, D., E. Mostert, W. Egas, S. Moellenkamp, C. PahlWostl, and R. Yalcin. 2009. Adaptive water governance: assessing the institutional prescriptions of adaptive (co-) management from a governance perspective and defining a research agenda. Ecology and society 14(1):26. [online] URL: http://www.ecologyandsociety. org/vol14/iss1/art26/

Kaplan, S., and B. J. Garrick. 1981. On the quantitative definition of risk. Risk Analysis 1:11-27. http://dx.doi.org/10.1111/ j.1539-6924.1981.tb01350.x

Kind, J. M. 2014. Economically efficient flood protection standards for the Netherlands. Journal of Flood Risk Management 7:103-117. http://dx.doi.org/10.1111/jfr3.12026

Klijn, F., N. Asselman, and H. Van Der Most. 2010. Compartmentalisation: flood consequence reduction by splitting up large polder areas. Journal of Flood Risk Management 3:3-17. http://dx.doi.org/10.1111/j.1753-318X.2009.01047.x

Klijn, F., M. J. P. Mens, and N. E. M. Asselman. 2015. Flood risk management for an uncertain future: economic efficiency and system robustness perspectives compared for the Meuse River (Netherlands). Mitigation and Adaptation Strategies for Global Change 20:1011-1026. http://dx.doi.org/10.1007/s11027-015-9643-2

Kok, M., H. Huizinga, A. Vrouwenfelder, and A. Barendregt. 2004. Standard method 2004. Damage and casualties caused by flooding. HKV Consultants, Lelystad, The Netherlands. [online] URL: http://library.wur.nl/ebooks/hydrotheek/1874298.pdf

Kolen, B., and I. Helsloot. 2012. Time needed to evacuate the Netherlands in the event of large-scale flooding: strategies and consequences. Disasters 36:700-722. http://dx.doi.org/10.1111/ j.1467-7717.2012.01278.x

Kolen, B., B. Maaskant, and T. Terpstra. 2013. Evacuatieschattingen Nederland addendum. Rapport, PR2753.10. HKV Consultancy, Delft, The Netherlands. 
Lebel, L., J. M. Anderies, B. Campbell, C. Folke, S. HatfieldDodds, T. P. Hughes, and J. Wilson. 2006. Governance and the capacity to manage resilience in regional social-ecological systems. Ecology and Society 11(1):19. [online] URL: http://www. ecologyandsociety.org/vol11/iss1/art19/

Maidl, E., and M. Buchecker. 2015. Raising risk preparedness by flood risk communication. Natural Hazards and Earth System Sciences 15:1577-1595. http://dx.doi.org/10.5194/nhess-15-1577-2015

Matczak, P., J. Lewandowski, A. Chorynski, M. Szwed, and Z. Kundzewicz. 2015. Flood risk governance arrangements in Europe. Proceedings of the International Association of Hydrological Sciences 369:195-199. http://dx.doi.org/10.5194/ piahs-369-195-2015

Mens, M. J. P. 2015. System robustness analysis in support of flood and drought risk management. Dissertation. IOS Press, Amsterdam, The Netherlands.

Mens, M. J. P., and F. Klijn. 2015. The added value of system robustness analysis for flood risk management illustrated by a case on the IJssel River. Natural Hazards and Earth System Science 15:213-223. http://dx.doi.org/10.5194/nhess-15-213-2015

Mens, M. J. P., F. Klijn, K. M. de Bruijn, and E. van Beek. 2011. The meaning of system robustness for flood risk management. Environmental Science \& Policy 14(8):1121-1131. http://dx.doi. org/10.1016/j.envsci.2011.08.003

Nelson, D. R., W. N. Adger, and K. Brown. 2007. Adaptation to environmental change: contributions of a resilience framework. Annual Review of Environment and Resources 32:395-419. http:// dx.doi.org/10.1146/annurev.energy.32.051807.090348

Pahl-Wostl, C. 2009. A conceptual framework for analysing adaptive capacity and multi-level learning processes in resource governance regimes. Global Environmental Change 19:354-365. http://dx.doi.org/10.1016/j.gloenvcha.2009.06.001

Pahl-Wostl, C., J. Sendzimir, P. Jeffrey, J. Aerts, G. Berkamp, and K. Cross. 2007. Managing change toward adaptive water management through social learning. Ecology and Society 12 (2):30. [online] URL: http://www.ecologyandsociety.org/vol12/ iss $2 / \operatorname{art} 30 /$

Potter, K. 2012. Battle for the floodplains: an institutional analysis of water management and spatial planning in England. Dissertation, University of Liverpool, Liverpool, UK.

Sendzimir, J., Z. Flachner, C. Pahl-Wostl, and C. Knieper. 2010. Stalled regime transition in the upper Tisza River Basin: the dynamics of linked action situations. Environmental Science \& Policy 13(7):604-619. http://dx.doi.org/10.1016/j.envsci.2010.09.005

Van Alphen, J. 2015. The Delta Programme and updated flood risk management policies in the Netherlands. Journal of Flood Risk Management. http://dx.doi.org/10.1111/jfr3.12183

Van Buuren, A., and G. J. Ellen. 2014. De governance van slimme combinaties. Spelregels voor samenwerking rond meerlaagse vormen van waterveiligheid. (Extern rapport, no 1208559-000). Deltares, Utrecht, The Netherlands.

Van Buuren, A., A. M. Keessen, C. Van Leeuwen, J. Eshuis, and G. J. Ellen. 2015. Implementation arrangements for climate adaptation in the Netherlands: characteristics and underlying mechanisms of adaptive governance. Ecology and Society 20 (4):11. http://dx.doi.org/10.5751/es-07704-200411

Van Staveren, M. F., and J. P. M. Van Tatenhove. 2016. Hydraulic engineering in the social-ecological delta: understanding the interplay between social, ecological, and technological systems in the Dutch delta by means of "delta trajectories." Ecology and Society 21(1):8. http://dx.doi.org/10.5751/ES-08168-210108

Vermeulen, C. J. M., J. van der Zwet, and R. M. van Dam. 2015. Compartimenteringskeringen dijkringen 17, 20, 21, 22 en 25. (Rapport, PR2511.30). HKV Consultants, Lelystad, The Netherlands. [online] URL: http://www.zuid-holland.nl/publish/ pages/12597/onderzoekcompartimenteringskeringenwshd.pdf

Williamson, P. J. 1999. Strategy as options on the future. Sloan Management Review 40(3):117-126. 